\title{
The Electrical Characteristics of Aluminium Doped Zinc Oxide Thin Film for Humidity Sensor Applications
}

\author{
N. D. Md Sin, M. Fuad Kamel, Rosalena Irma Alip, Zulfakri Mohamad, and M. Rusop \\ Nano-Electronic Centre, Faculty of Electrical Engineering, University Teknologi Mara, 40450 Shah Alam, Selangor, Malaysia \\ Correspondence should be addressed to N. D. Md Sin, deems001@gmail.com
}

Received 15 April 2011; Revised 29 May 2011; Accepted 6 June 2011

Academic Editor: A. John Peter

Copyright () 2011 N. D. Md Sin et al. This is an open access article distributed under the Creative Commons Attribution License, which permits unrestricted use, distribution, and reproduction in any medium, provided the original work is properly cited.

\begin{abstract}
The electrical characteristics of aluminum ( $\mathrm{Al})$ doped zinc oxide $(\mathrm{ZnO})$ thin film for high sensitivity humidity sensors are presented. The effects of $\mathrm{Al}$ doping concentration at $0 \sim 0.6$ at $\%$ on the $\mathrm{Al}$ doped $\mathrm{ZnO}$ thin film properties were investigated using current-voltage measurement. The optical and structural properties were characterized using photoluminescence (PL), scanning emission microscope (SEM), and X-ray diffraction (XRD). Parameter 0.6 at \% Aluminum doped show high sensitivity and suitable for humidity sensor. PL show an emissions band with two peaks centered at about $380 \mathrm{~nm}$ (ultra-violet (UV)) and $600 \mathrm{~nm}$ (green) in a room temperature. The length of the nanorods increases as the doping concentration increases. XRD results show the intensity of the (002) peak decreased with the increasing of doping concentration.
\end{abstract}

\section{Introduction}

$\mathrm{ZnO}$ is n-type semiconductor with wide band gap $3.37 \mathrm{eV}$ posses wurtzite family structure. It has many potentials in electronics devices such as sensors. Humidity sensor is essential to sense the moisture of the environment to control the human comfort, industry packaging [1], and semiconductor manufacturing [2]. For humidity sensor application, highly active surface properties exhibit better sensitivity [2-5]. Sensing mechanism of sensor is based on the adsorption and desorption process, the surface are reaction with the water vapor to determine the sensing properties [4]. Recently, onedimensional (1D) $\mathrm{ZnO}$ nanostructure such as nanowire, and nanorod, nanobelts nanoneedle give advantage in sensor properties $[6,7]$.

$\mathrm{ZnO}$ thin film have been prepared using various method such as sol-gel [3], vapor-phase transport [8], and hydrothermal [9]. To increase the performance of the sensor, doping can lowered the resistivity of semiconductor. Wang et al. reported $\mathrm{Pd}^{2+}$ act as catalytic to improve reactions of $\mathrm{ZnO}$ for sensor performance [8]. Aluminium was choose by Weon et al. to improve the vapor sensing characteristics by sol-gel process $[10,11]$. Nanorod $\mathrm{ZnO}$ thin film has been prepared in this study for humidity sensor application. The seed catalyst layer influence the growth of nanorod $\mathrm{ZnO}$.
In this study, we investigated characteristic of humidity sensor for Al-doped $\mathrm{ZnO}$ using sol-gel immersion method on the glass substrate. The doping concentration were vary for undoped $\mathrm{ZnO}, 0.4$ at $\%$ and 0.6 at $\% \mathrm{Al}$-doped $\mathrm{ZnO}$. The objective of this study is to study the effect of Al-doped $\mathrm{ZnO}$ toward humidity sensitivity.

\section{Methodology}

2.1. Material Preparation. At first the glass substrate were cleaned using standard cleaning method to remove all the contamination. For the template preparation, the glass substrate were sputtered with platinum for $30 \mathrm{~nm}$ at first and followed by gold for $30 \mathrm{~nm}$. $\mathrm{ZnO}$ solution were prepared using zinc acetate dehydrate $\left(\mathrm{Zn}\left(\mathrm{CH}_{3} \mathrm{COO}\right)_{2} \cdot 2 \mathrm{H}_{2} \mathrm{O}\right)$ as precursor, monoethanolamine (MEA) as stabilizer, 2methoxyethanol as solvent. The molar ratio of MEA to zinc acetate dehydrate were fixed at $1: 1$. All the material were mixed together using sol-gel method and were stirred at $80^{\circ} \mathrm{C}$ for 3 hour to yield a clear and homogeneous solution. The solution were aged for 24 hour at room temperature. Then, the substrate that have been coated were deposited by spincoating technique using sol-gel $\mathrm{ZnO}$ solution. The coating solution will be dropped onto the substrates, which were rotated at $3000 \mathrm{rpm}$ for $60 \mathrm{~s}$. After the spin coating the film 


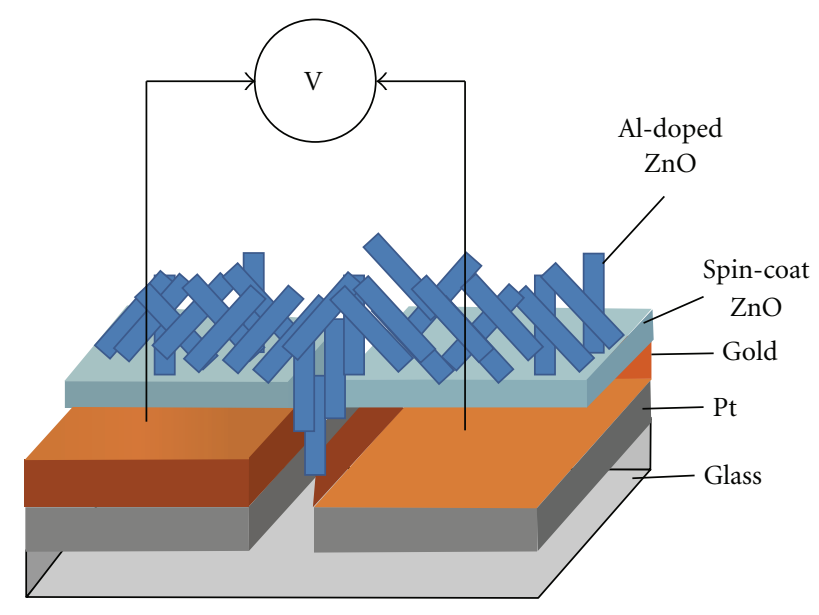

Figure 1: The cross-section of the sample.

were dried at $150^{\circ} \mathrm{C}$. This coating and drying process were repeated for 10 times to increase thickness for every sample. Then a trench was made for resistance action. The cross section of the thin film was made as shown in Figure 1.

Next, preparation for second sol-gel solution for the catalyst. In this solution, hexamethylenetetramine (HMT) act as the stabilizer, zinc acetate dehydrate $\left(\mathrm{Zn}\left(\mathrm{CH}_{3} \mathrm{COO}\right)_{2} \cdot 2 \mathrm{H}_{2} \mathrm{O}\right)$ as starting material and Aluminum Nitrate nanohydrate $\left(\mathrm{Al}\left(\mathrm{NO}_{3}\right)_{3} \cdot 9 \mathrm{H}_{2} \mathrm{O}\right)$ as dopant source were mixed into the deionized water that act as the solvent. The quantities of aluminum nitrate will be varying to achieve $0 \sim 0.6$ at $\%$ doping concentration in the $\mathrm{ZnO}$ solution. The solution was stir on the magnetic stirrer hot plate at $60^{\circ} \mathrm{C}$ for 3 hours then continue for another 24 hours in room temperature for ageing period. The container contains sol-gel solution with different doping concentration. The container immerse into the water bath that were heated at $95^{\circ} \mathrm{C}$ for 4 hours. Then the thin film were rinsed with deionizer water to remove the residual. After take out from the water bath, the samples were dried in for 10 minutes at $150^{\circ} \mathrm{C}$ and then annealed at $550^{\circ} \mathrm{C}$ for 2 hours.

The samples characterization stage involved determination of electrical properties by 2 probe $I-V$ measurement (Keithley 2400) in the humidity controlled box, optical properties using Photoluminescence (Horiba Jobin YvonDU420A-OE-325 system), surface morphology using Scanning Electron Microscopy (JEOL JSM 6701F).

2.2. Humidity Measurement. A homemade humidity box that made from polystyrene box with size about $40 \mathrm{~cm} \times$ $30 \mathrm{~cm} \times 25 \mathrm{~cm}$. A diagram of and photo the humidity box is shown in Figures 2(a) and 2(b) respectively. Two probe were used as the resistance measurement by attach the probe to the Keithley 2400. Hygrometer was place in the box to detect the changes of the humidity and also act as the indicator of the ambient inside the box. Moisturizer was placed to moisturize the environment in the box to increase the relative humidity $\%$ and silica gel were used to absorb the moisture in the humidity box. Two small window at top and bottom box were made for exhausting humid air to allow its flow in and out of the box. A small exhaust fan was placed near to the bottom window. Top window was used to take out the humid air inside the box. The RH\% measurement was varied from $40 \%$ to $90 \%$ RH by constant the temperature value. The sensor was placed inside the humid box and the two probe were attach at the metal contact of the thin film.

\section{Result and Discussion}

3.1. Electrical Properties. The sensor measurement for $I-V$ measurement using Keithley 2400 at room temperature is shown in Figure 3 for undoped $\mathrm{ZnO}, 0.4$ at $\%$ and 0.6 at $\%$ $\mathrm{Al}$-doped $\mathrm{ZnO}$. Current increase as more $\mathrm{Al}$ dopant are introduce as shown in Figure 3 compare to undoped $\mathrm{ZnO}$. The $I-V$ curves show the resistance of 0.6 at $\%$ Al-doped $\mathrm{ZnO}$ thin film is the lowest compare with other thin film and undoped $\mathrm{ZnO}$ is the lowest in electrical behaviour. This is due to the more free electron will be generated and increase the sensitivity of humidity sensor application [10]. The substitution produces 1 free electron which increase the carrier concentration in the thin film [12].

Figures 4, 5 and 6 shows the current versus voltage graph of $\mathrm{Al}$-doped $\mathrm{ZnO}$ for 0 at $\%, 0.4$ at $\%$ and 0.6 at $\%$ at different RH (\%). The current value increased proportionally with humidity due to the changes of the resistance. This case is due to the condition where the water vapor is absorbed by the structure of $\mathrm{Al}$-doped $\mathrm{ZnO}$. The existence of water vapour helps the current flow with less resistance thus more current can pass through the sample. This shows that the Al-doped $\mathrm{ZnO}$ material has the ability to absorb water vapor from the surroundings. It can verify that the Al-doped $\mathrm{ZnO}$ can increase the sensitivity of the humidity sensor.

Figure 7 show the resistance of the sample at different $\mathrm{Al}$ doping concentrations. The resistance was obtained using following equation:

$$
R=\frac{V}{I}
$$

$R$ is resistance, $V$ is voltage and $I$ is current. All samples shows uniform changes from $30 \%$ to $90 \% \mathrm{RH}$. The significant different of resistance from $16.6 \mathrm{k} \Omega$ to $16.7 \mathrm{M} \Omega$ occurred for 0.6 at $\%$ Al-doped $\mathrm{ZnO}$ compare to other samples.

Sensitivity in this project is referred as the response of the resistance due to the changes of relative humidity. The value of the sensitivity was measured by taking the slope of the resistance versus relative humidity graph. Figure 8 show the comparison of the sensitivity between both $\mathrm{Al}$ doping. The sensitivity was obtained using following equation:

$$
S=\frac{\Delta R}{\Delta \% \mathrm{RH}}=\frac{\Delta \text { Resistance }}{\Delta \% \text { Relative humidity }}
$$

$R$ is resistance, $S$ is sensitivity and RH is relative humidity

From that graph shows the sample with 0.6 at $\% \mathrm{Al}-$ doped $\mathrm{ZnO}$ has a higher sensitivity than other thin film. All the sensors roughly exhibit the region of sensitivity, as for example, when the value of relative humidity is higher the sensitivity will increase. 


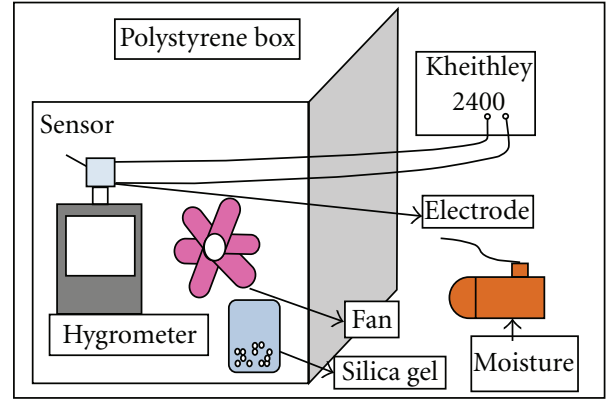

(a)

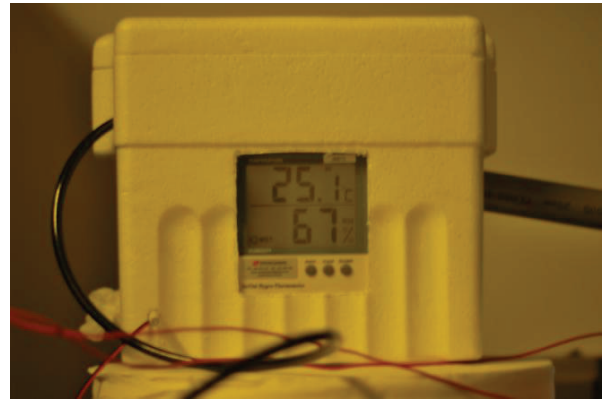

(b)

Figure 2: (a) The humidity box diagram. (b) The photo of humidity box.

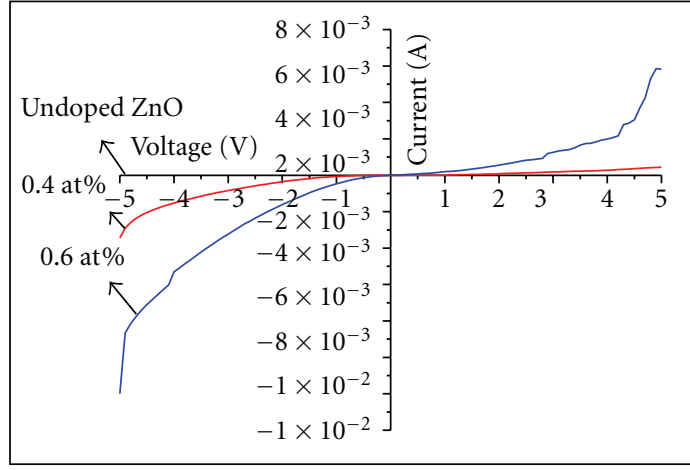

Undoped
$0.4 \mathrm{at} \%$
$-0.6 \mathrm{at} \%$

Figure 3: The graph for $I-V$ measurement at room temperature.

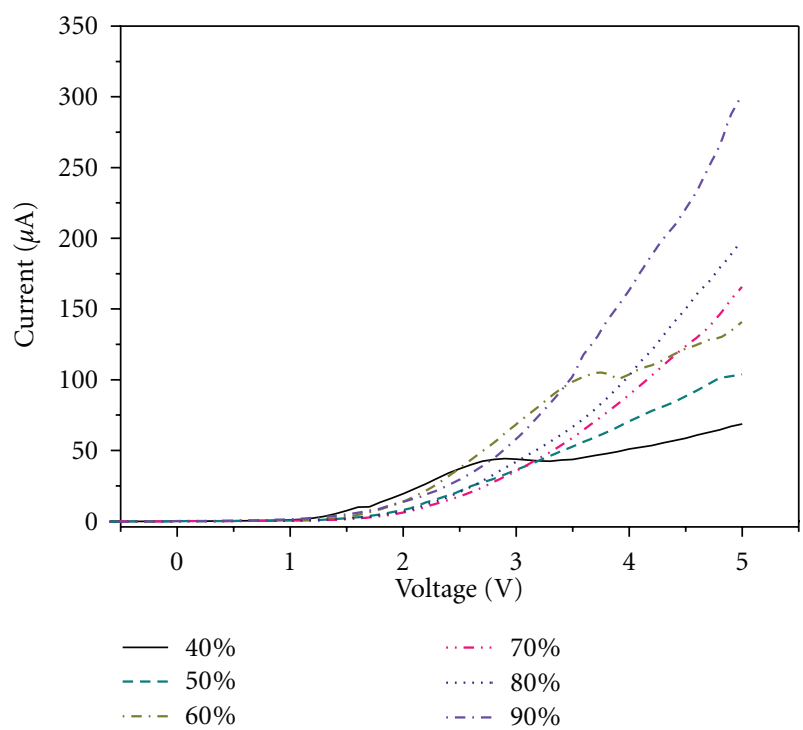

FIGURE 4: $I-V$ graph for aluminum undoped.

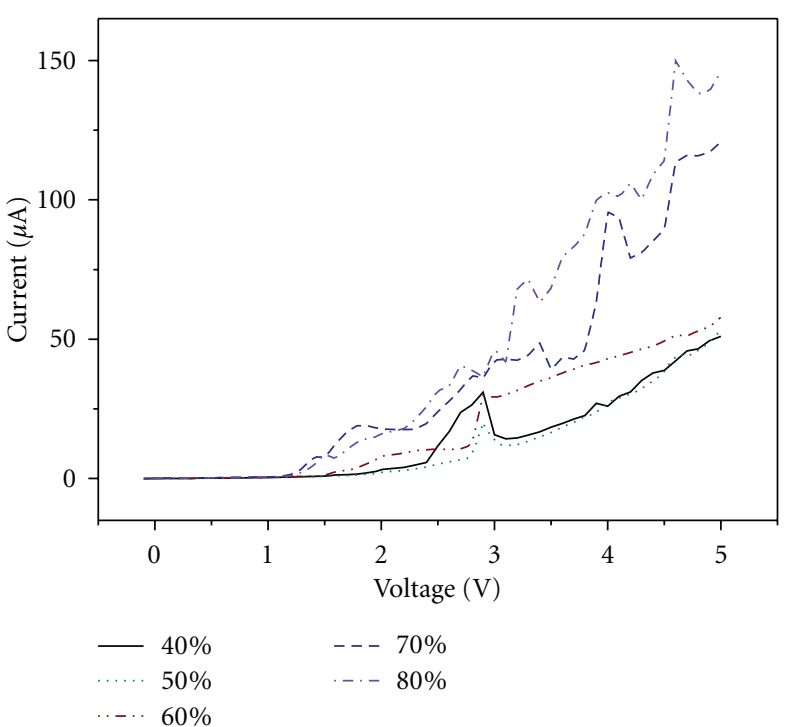

Figure 5: $I-V$ graph for aluminum doped 0.4 at $\%$.

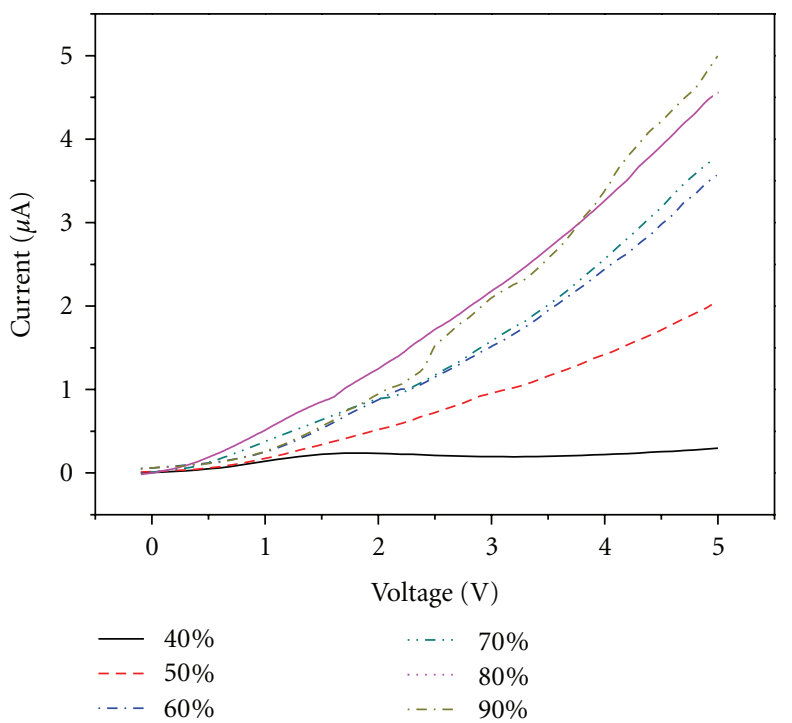

FIgURE 6: $I-V$ graph for aluminum doped 0.6 at $\%$. 


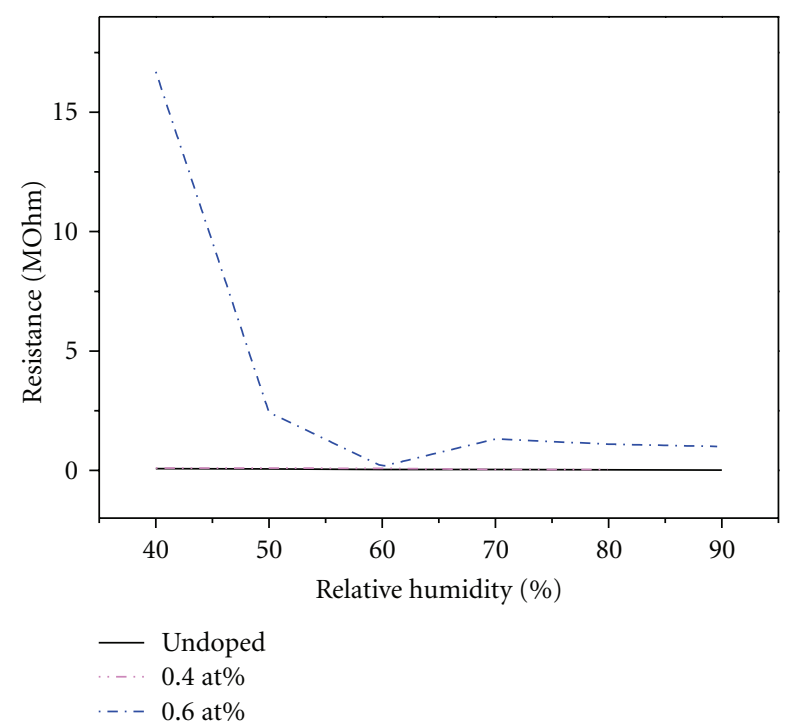

FIGURE 7: Resistance versus relative humidity, RH\%.

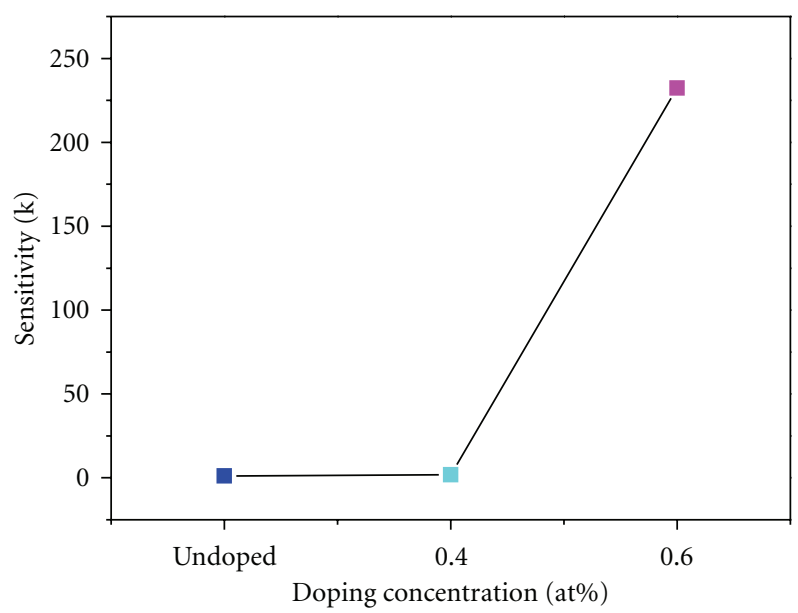

FIgURE 8: Sensitivity versus doping concentration (at\%).

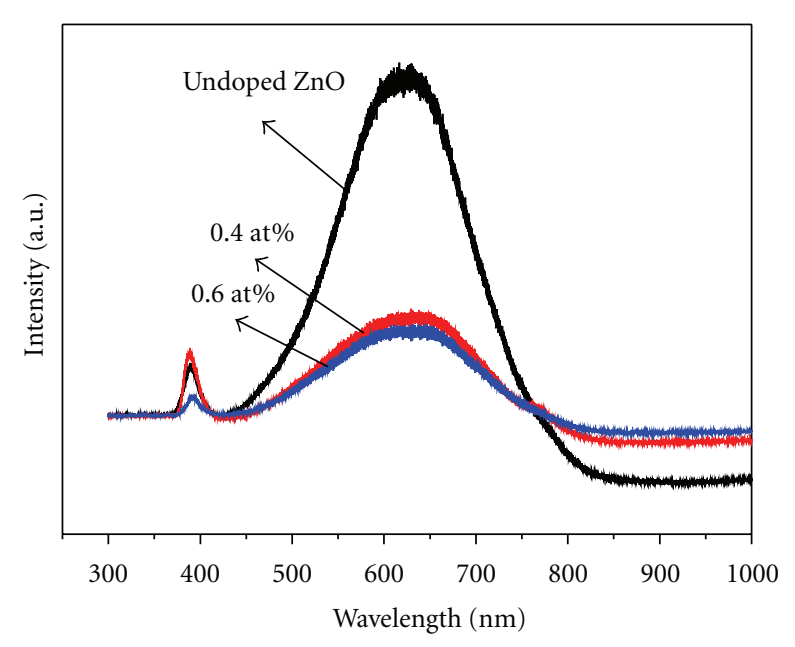

FIgURE 9: PL measurement at room temperature.

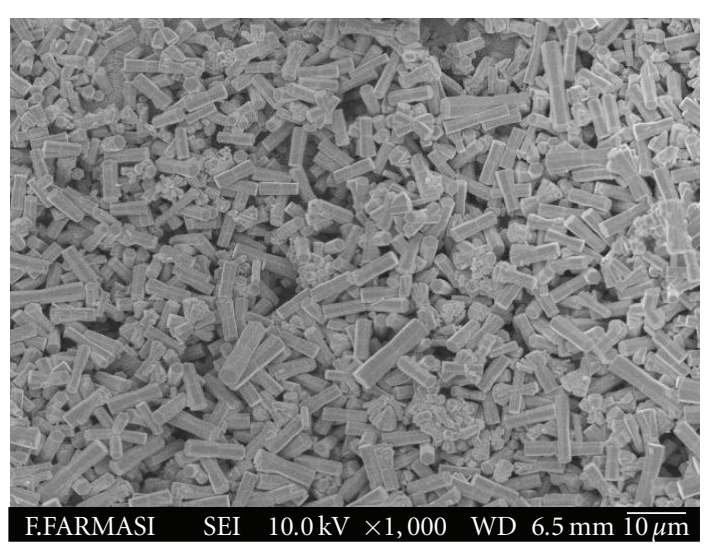

(a) 0 at $\%$

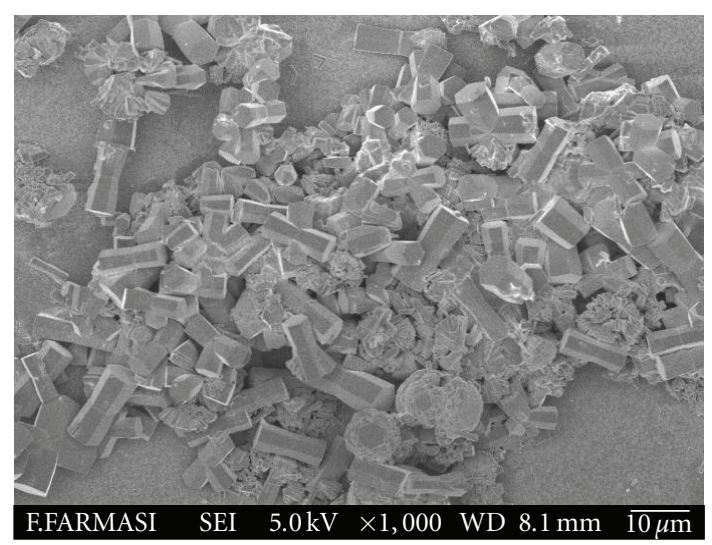

(b) 0.4 at $\%$

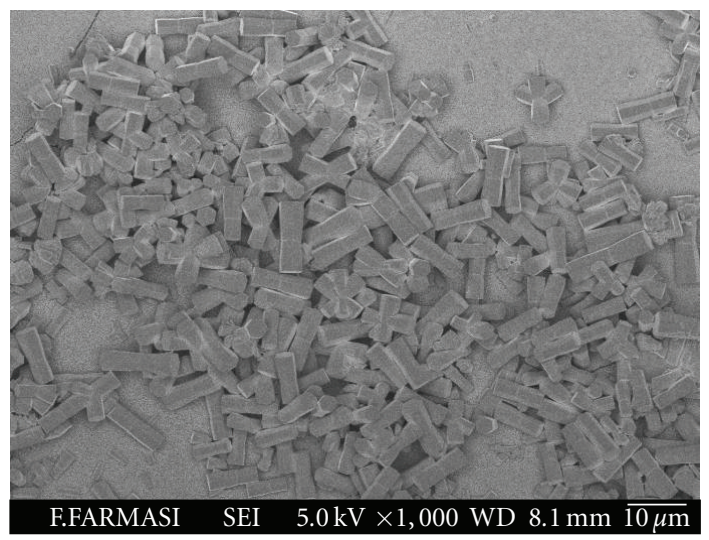

(c) 0.6 at $\%$

Figure 10: SEM image of the $\mathrm{Al}$ doped $\mathrm{ZnO}$ thin films deposited at.

This explained the current measured in this project are always increasing as the relative humidity increase. The 0.6 at $\% \mathrm{Al}$-doped $\mathrm{ZnO}$ thin films having more sensitivity than the 0 at $\%$ and 0.4 at $\%$ are because of the adsorption of the moisture molecules by the $\mathrm{Al}$-doped $\mathrm{ZnO}$ at the surface of both samples. There for the high sensitivity is $2.32 \mathrm{M}$ $(\Omega / \mathrm{RH})$ at $0.6 \%$ doping Al-doped $\mathrm{ZnO}$. 


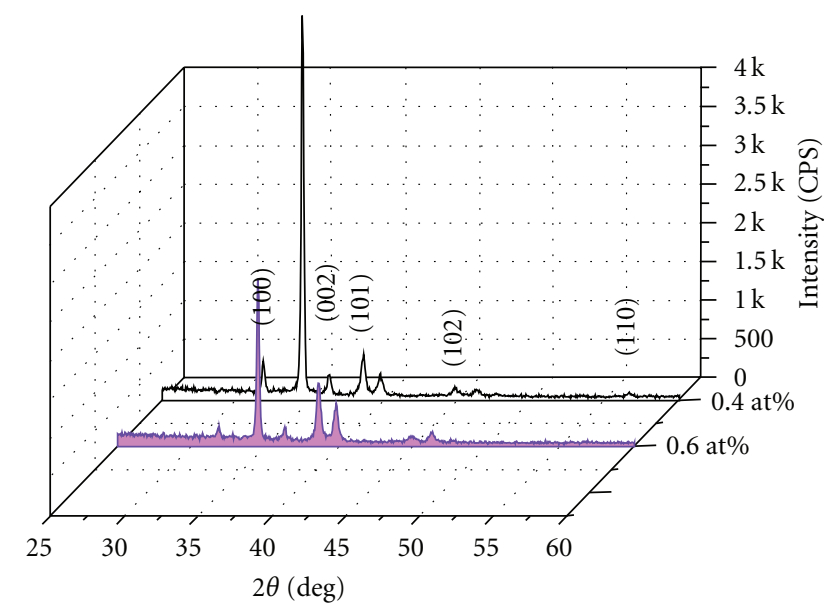

FIGURE 11: XRD pattern of the $\mathrm{Al}$ doped $\mathrm{ZnO}$ thin films deposited at 0.4 at $\%$ and 0.6 at $\%$.

3.2. Optical Properties. The PL spectra of undoped $\mathrm{ZnO}$ and $\mathrm{Al}$-doped $\mathrm{ZnO}$ at room temperature are plotted in Figure 9. The PL spectra of undoped $\mathrm{ZnO}$ and $\mathrm{Al}$-doped $\mathrm{ZnO}$ show two distinct peaks at about $380 \mathrm{~nm}$ in the UV region and $600 \mathrm{~nm}$ at broad green band. The UV emission give excitonic recombination corresponding to the band edge emission. The variation in visible emission intensity at $600 \mathrm{~nm}$ was attributed to the probability of formation of defects dominated by dopant concentration. The UV-to-green emission ratio decrease as the doping concentration increase.

3.3. Surface Morphology. SEM image in Figure 10 show $\mathrm{Al}$ doped $\mathrm{ZnO}$ thin films deposited at different doping concentrations. Figure 10(a) show that a $\mathrm{ZnO}$ nanorods deposited on the sol-gel spin-coat $\mathrm{ZnO}$ thin film coated glass substrate. The Al-doped $\mathrm{ZnO}$ nanorods have been show in Figures 10(b) and 10(c). The nanorod that show in Figure 10 for all doping concentration are in hexagonal shape. The length of the nanorods increase as the doping concentration increase. Highly surface area lead to increase the sensitivity due to more site area to absorb $[2,10]$. The nanoparticles that have been coated on the gold contact does influence the size of nanorods $\mathrm{ZnO}$ due to the nucleation growth [12].

Figure 11 show the XRD pattern of 0.4 at $\%$ and 0.6 at $\% \mathrm{Al}$-doped $\mathrm{ZnO}$ thin films. Both thin films exhibit polycrystalline structure that belongs to the hexagonal wurtzite type of $\mathrm{ZnO}$ (JCPDS \#36-1451). Five diffraction peaks have been showed for all samples in diffraction angle beetween $25^{\circ}$ and $60^{\circ}$ which can be indexed to (100), (002), (101), (102), and (110) planes. XRD results show the intensity of the (002) peak decreased with the increasing of doping concentration. [12].

\section{Conclusion}

The particles of zinc oxide had been grown successfully on the glass substrate by sol gel method. The electrical properties of Al-doped $\mathrm{ZnO}$ are investigated by using the $I-V$ measurement in the humidity box. The $I-V$ measurement shows that the sensitivity is high when the 0.6 at. Al-doped was used compare to the other parameter in this project. Therefore, parameter 0.6 at $\% \mathrm{Al}$-doped is suitable for humidity sensor. PL spectra indicate that UV emission centered at about $380 \mathrm{~nm}$, and the variation in visible emission intensity at $600 \mathrm{~nm}$ was attributed to the probability of formation of defects dominated by dopant concentration. The grain size due to aluminum dopant was characterized by SEM.

\section{Acknowledgments}

The author likes to express her thanks to Institute Of Science, Faculty of Pharmacy UiTM and Faculty of Mechanical UiTm for providing the laboratory facilities.

\section{References}

[1] N. Zhang, K. Yu, Z. Zhu, and D. Jiang, "Synthesis and humidity sensing properties of feather-like $\mathrm{ZnO}$ nanostructures with macroscale in shape," Sensors and Actuators A, vol. 143, no. 2, pp. 245-250, 2008.

[2] Y. Zhang, K. Yu, D. Jiang, Z. Zhu, H. Geng, and L. Luo, "Zinc oxide nanorod and nanowire for humidity sensor," Applied Surface Science, vol. 242, no. 1-2, pp. 212-217, 2005.

[3] A. Erol, S. Okur, B. Comba, Ö. Mermer, and M. C. Arikan, "Humidity sensing properties of $\mathrm{ZnO}$ nanoparticles synthesized by sol-gel process," Sensors and Actuators B, vol. 145, no. 1, pp. 174-180, 2010.

[4] H. K. Kim, S. D. Sathaye, Y. K. Hwang et al., "Humidity sensing properties of nanoporous TiO2-SnO2 ceramic sensors," Bulletin of the Korean Chemical Society, vol. 26, no. 11, pp. 1881$1884,2005$.

[5] Q. Kuang, C. Lao, Z. L. Wang, Z. Xie, and L. Zheng, "Highsensitivity humidity sensor based on a single $\mathrm{SnO} 2$ nanowire," Journal of the American Chemical Society, vol. 129, no. 19, pp. 6070-6071, 2007.

[6] L. Schmidt-Mende and J. L. MacManus-Driscoll, " $\mathrm{ZnO}$ nanostructures, defects, and devices," Materials Today, vol. 10, no. 5, pp. 40-48, 2007.

[7] Z. L. Wang, "Nanostructures of zinc oxide," Materials Today, vol. 7, no. 6, pp. 26-33, 2004.

[8] X. Wang, J. Zhang, Z. Zhu, and J. Zhu, "Humidity sensing properties of Pd2+-doped $\mathrm{ZnO}$ nanotetrapods," Applied Surface Science, vol. 253, no. 6, pp. 3168-3173, 2007.

[9] W. Yun, T. W. Y. John, Senior Member IEEE, and C. LiangYih, "Synthesis of aligned zinc oxide nanorods for humidity sensing," in Proceedings of the 3rd International Conference on Sensing Technology (ICST '08), pp. 670-673, December 2008.

[10] W. P. Tai and J. H. Oh, "Humidity sensing behaviors of nanocrystalline Al-doped $\mathrm{ZnO}$ thin films prepared by sol-gel process," Journal of Materials Science: Materials in Electronics, vol. 13, no. 7, pp. 391-394, 2002.

[11] W. P. Tai and J. H. Oh, "Humidity sensitive properties of nanostructured Al-doped $\mathrm{ZnO}$ : TiO 2 thin films," Sensors and Actuators B, vol. 96, no. 3, pp. 477-481, 2003.

[12] M. H. Mamat, M. Z. Sahdan, Z. Khusaimi, A. Z. Ahmed, S. Abdullah, and M. Rusop, "Influence of doping concentrations on the aluminum doped zinc oxide thin films properties for ultraviolet photoconductive sensor applications," Optical Materials, vol. 32, no. 6, pp. 696-699, 2010. 

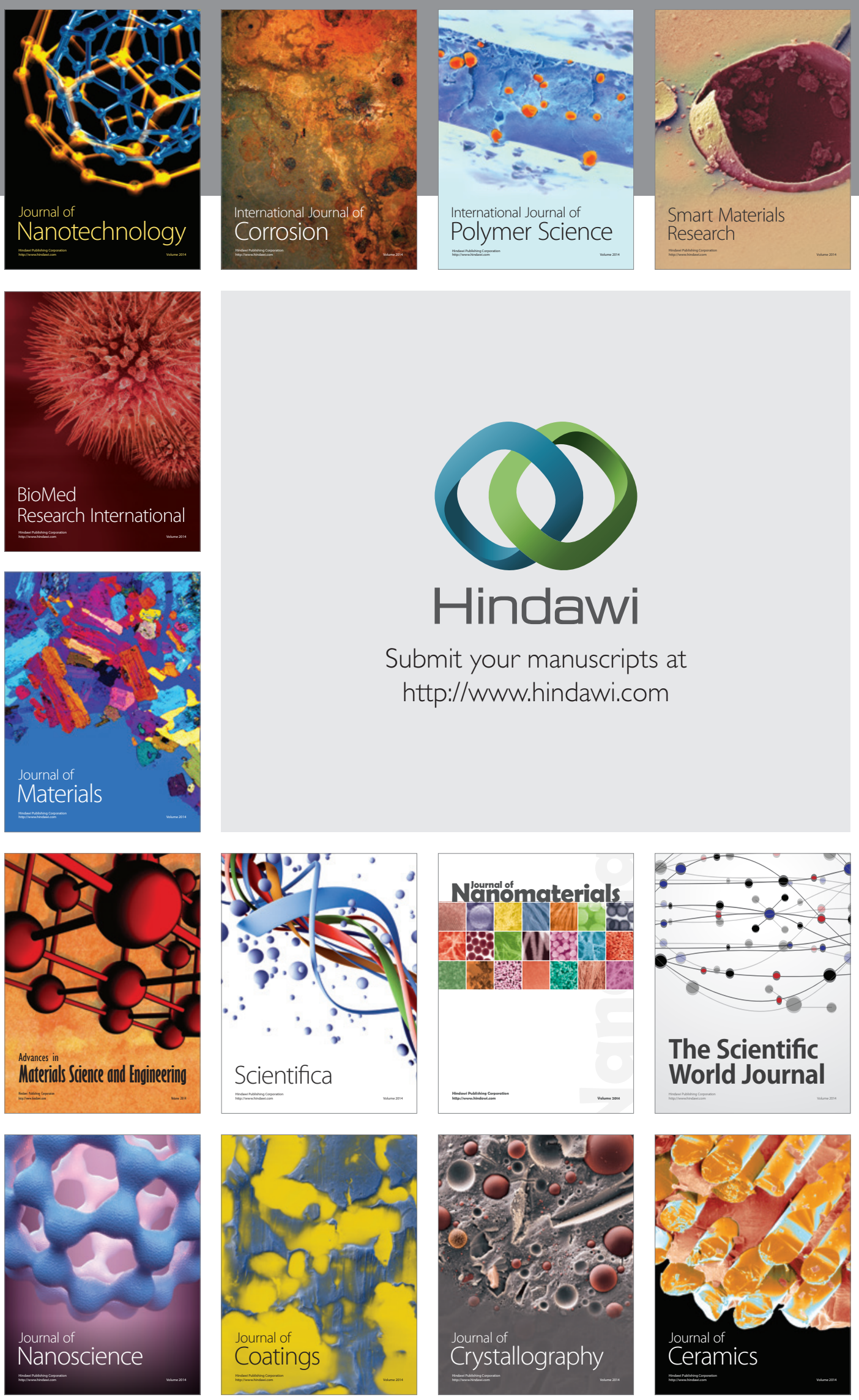

The Scientific World Journal

Submit your manuscripts at

http://www.hindawi.com

\section{World Journal}

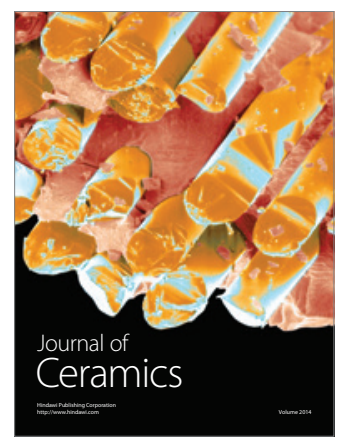

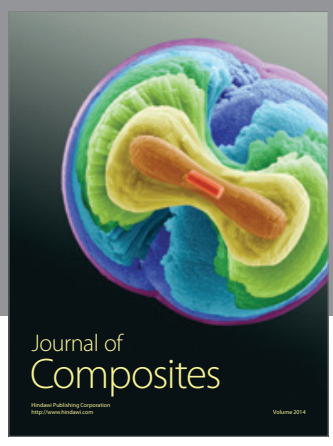
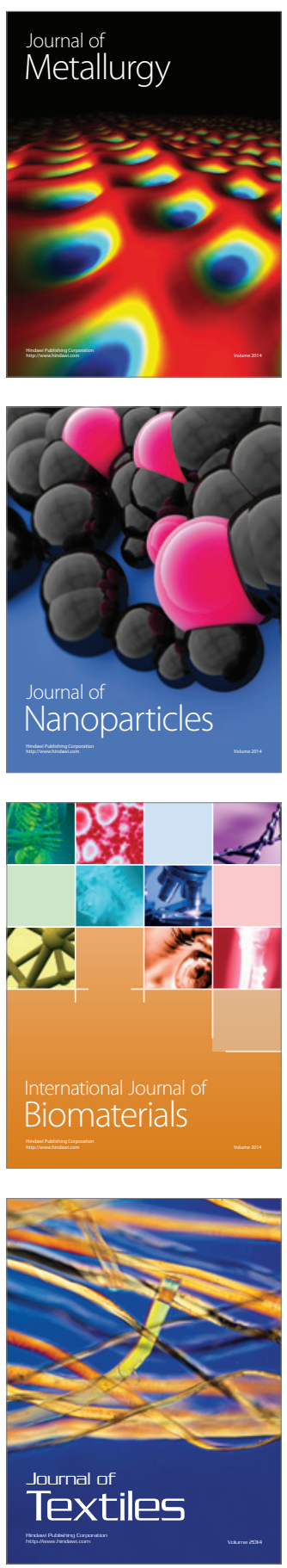